\title{
O AVESSO DOS DIREITOS DAS \\ CRIANÇAS: A ERRADICAÇÃO DO \\ TRABALHO INFANTIL EM DEBATE
}

Maria dos Anjos Lopes Viella ${ }^{1}$

Célia Regina Vendramini ${ }^{2}$

Resumo: Este texto situa duas perspectivas contraditórias em relação à erradicação do trabalho infantil: a perspectiva da OIT (Organização Internacional do Trabalho) defendendo a sua erradicação e outra contrária a ela, defendendo a valorização crítica do trabalho realizado pelas crianças, perspectiva essa que insiste no protagonismo infantil, isto é, na necessidade de dar voz às crianças dimensionando o que elas têm a dizer sobre o trabalho.

Palavras-chave: Trabalho infantil. Protagonismo infantil. Erradicação do trabalho infantil. Direitos das crianças. 


\section{Introdução}

O debate que se vê instalado sobre o trabalho infantil apresenta duas vertentes. Ambas se posicionam na defesa dos direitos da criança. Uma é da OIT que propõe a erradicação dessa forma de trabalho e a outra critica duramente a posição da OIT, defendendo o direito das crianças ao trabalho, exceto nas suas piores formas. Alguns autores dessa segunda vertente afirmam que a proibição do trabalho infantil tem culminado na sua realização de formas mais precarizadas e clandestinas.

A primeira perspectiva, aqui denominada de abolicionista, considera toda e qualquer forma de trabalho desempenhado por menores como incompatível com os direitos da criança e, por consequiência, propõe a sua erradicação. A perspectiva que defende o protagonismo infantil, istoé, o direito das crianças ao trabalho, considera-o inerente à condição social contemporânea da infância e, portanto, recusa as políticas abolicionistas, propondo a aceitação "realista" do trabalho infantil.

É importante assinalar que "[...] as décadas de setenta e oitenta, assistiram a uma verdadeira erupção da pessoa humana no Direito Internacional. Os anos internacionais da Mulher, da Criança, da Juventude, do Deficiente sinalizam claramente uma tendência irreversível nessa direção" (COSTA, 1992, p.17). Quanto aos direitos da criança, pode-se ressaltar nessa caminhada o início em 1923, como o ano em que a União Internacional "Save the Children" redigiu e aprovou a Declaração de Genebra e em 1924, a Quinta Assembléia da Sociedade das Nações também a aprova. Terminada a II Guerra, a ONU (Organização das Nações Unidas) aprova Declaração que amplia os direitos contidos no texto de 1924 e onze anos depois, em 1959, a Assembléia Geral da ONU aprova os Direitos da Criança. Em 1979 é declarado o Ano Internacional da Criança e, em 1989, em 20 de novembro, aprova-se a Convenção Internacional dos Direitos da Criança.

A década de 1980, no Brasil, pode ser considerada um marco na luta em favor dos direitos sociais das crianças com sua extensão na década de 1990: a promulgação da Constituição Federal de 1988; a adoção, em 1989, da Convenção das Nações Unidas sobre os Direitos da Criança; a aprovação, em 1990, doECA(Estatuto da Criança e do Adolescente); o IPEC (Programa Internacional para a Eliminação do Trabalho Infantil) em 1992, e a criação, em 1994, do FNPETI ( Fórum Nacional de Prevenção e Erradicação do 
Trabalho Infantil) como espaço para reunir e articular os poderes envolvidos em políticas e programas de prevenção e erradicação do trabalho infantil (entidades do Governo Federal, organização de empregadores e trabalhadores, ONGs, Procuradoria Geral da República e Ministério Público do Trabalho); os programas do UNICEF (Fundo das Nações Unidas para a Infância) passam a incluir, a partir de 1992, o tema do trabalho infantil na agenda de políticas sociais e econômicas.

A história da legislação sobre trabalho infantil é longa. Olhando para a OIT, como organismo responsável pelo controle e emissão de normas referentes ao trabalho em todo o mundo, determinando as garantias mínimas ao trabalhador, tem-se uma visão da centralidade dada ao trabalho infantil principalmente sob o ponto de vista das Convenções e Recomendações.

Desde sua criação em 1919, a OIT tem realizado inúmeras ações na luta contra o trabalho infantil na adoção de Convenções e Programas ${ }^{3}$. A Primeira Conferência Internacional do Trabalho (1919) adota a Convenção n ${ }^{\circ} 5$ sobre a idade mínima de trabalho (indústria). Em 1930, a adoção da primeira Convenção que dispõe sobre a eliminação do Trabalho Forçado ou obrigatório em todas as suas formas; em 1973, a adoção da Convenção 138 sobre a Idade Mínima; em 1999, defende a adoção de medidas imediatas e eficazes que garantam a proibição e a eliminação das Piores Formas de Trabalho Infantil (Convenção 182); em 2002, estabelece o dia 12 de junho como Dia Mundial de Combate ao Trabalho Infantil.

$\mathrm{Na}$ perspectiva de lutar contra o trabalho infantil, a OIT apresenta o Convênio 182 sobre as piores formas de trabalho infantil, também denominadas "formas extremas", "formas intoleráveis". São consideradas como piores formas de trabalho infantil aquelas "que dañen la seguridad, la salud mental y física e, incluso, a veces la vida del niño". Em virtude do Artigo 3 do Convênio, as piores formas de trabalho infantil são:

-Todas las formas de esclavitud o las prácticas análogas a la esclavitud, como la venta y el tráfico de niños, la servidumbre por deudas y la condición de siervo, y el trabajo forzoso u obligatorio, incluido el reclutamiento forzoso u obligatorio de niños para utilizarlos en conflictos armados;

- La utilización, el reclutamiento o la oferta de niños para la prostitución, la producción de pornografía o actuaciones pornográficas; 
- La utilización, el reclutamiento o la oferta de niños para la realización de actividades ilícitas, en particular la producción y el tráfico de estupefacientes, tal como se definen en los tratados internacionales pertinentes;

- El trabajo que, por su naturaleza o por las condiciones en que se lleva a cabo, es probable que dañe la salud, la seguridad o la moralidad de los niños. (OIT. Guia sobre las normas internacionales del trabajo ([s.d], p.31).

Ao se eleger determinadas formas de trabalho infantil como as piores, supõe-se que as outras formas não sejam tão más e, portanto, possam continuar existindo, pois são mais adequadas, mais aceitáveis. Uma análise dos Mapas de Indicativos do trabalho da criança e do adolescente no Brasil (1999 e 2005), no tocante às condições de trabalho a que estão submetidos deixa estampada a impossibilidade de eleger entre todas as atividades mencionadas, aquelas que não causem danos à saúde, à segurança e moralidade.

Como todas as leis são produtos de suas épocas e refletem as concepções do social que perpassam cada período, em relação às histórias das políticas sociais dirigidas à criança até a era do Estatuto da Criança e do Adolescente de 1990, transita-se de uma visão higienista e correcional da infância, atrelada à condição e invenção do menor, do menor em situação irregular, menor enquanto objeto de medidas judiciais, como questão de segurança nacional até a criança cidadã, sujeito de direitos.

Os clientes potenciais desses aparatos jurídicos são aqueles para quem a distribuição justa de renda não passa de discurso e para os quais o trabalho se apresenta como a atividade mais nobre que o homem deve exercer, remédio para muitos males, antídoto ao crime, à marginalidade.

O Relatório Global OIT - 2006 sobre trabalho infantil traz, no primeiro parágrafo do Prefácio, que apesar da luta contra o trabalho infantil continuar a ser um desafio enorme, assiste-se a sua redução, especialmente em suas piores formas e aponta que o fim deste problema depende da vontade, dos recursos e das decisões políticas.

Apesar das declarações de redução e intenções da viragem significativa, o trabalho infantil parece não dar motivos para celebração, pois o que se observa na análise dos mapas de indicativos do trabalho da criança e do adolescente (1999 e 2005) é a enorme diversificação das atividades 
econômicas exercidas por crianças, a reinvenção do trabalho nas mais variadas formas, permitindo problematizar a anunciada redução. Trabalho de adultos e crianças são igualados entre si e reduzidos a apenas trabalho, trabalho humano abstrato. É nessa indiferenciação qualitativa dos diferentes trabalhos que o trabalho infantil deve ser considerado. Desde que o trabalho se materialize nos produtos, e que seja trabalho humano abstrato, não importa de onde provenha o quantum de trabalho, se do adulto ou da criança.

As estatísticas apresentadas são contraditórias. Muitas análises são controversas. Em Nota Técnica /2006, cujo assunto é análise dos dados sobre trabalho infantil na PNAD 2005, a Secretaria de Avaliação e Gestão da Informação do Ministério do Desenvolvimento Social e Combate à Fome aponta um ligeiro crescimento na Taxa de Ocupação das pessoas cinco a dezessete a 17 anos de idade. Este aumento na taxa de ocupação é notado na faixa de cinco a nove anos e dez a quatorze e redução na faixa de quinze a dezessete.

Organizações do mundo inteiro se mobilizam na luta contra as formas abusivas do trabalho infantil culminando nas mais diversas ações, convênios, protocolos, recomendações com vistas para erradicar esse tipo de trabalho. É preciso, entretanto, compreender em profundidade o sentido e a direção que ele assume no interior da sociedade capitalista.

O capítulo VIII de O Capital, sobre a jornada de trabalho é um dos que retrata com maiores detalhes a falta de limites legais à exploração do trabalho em geral, mas especificamente do trabalho infantil. Marx (2002, p.297) coloca a voracidade do capital pelo trabalho excedente e os abusos daí decorrentes, frutos da "sede vampiresca [...] pelo sangue vivificante do trabalho".

Falar da redução do trabalho infantil é quase uma fábula, numa '[...] sociedade de consumo produtora de desperdício, que depende para seu ciclo de reprodução "industrial-moderno", não apenas da mais cínica manipulação da demanda dos consumidores, mas também da mais desumana exploração dos “despossuídos”" (MESZÀROS, 2002, p.1005), entretanto a OIT anuncia "A eliminação do trabalho infantil: um objetivo ao nosso alcance" no pomposo título de seu Relatório Global de 2006.

Dividido em quatro partes o Relatório, apresenta, na I Parte, um quadro global no qual se delineiam as tendências do trabalho infantil, referindo-se aos progressos nacionais e as políticas que contribuem na redução desse tipo de trabalho em todo o mundo. A II Parte analisa as ações da OIT 
contra o trabalho infantil desde 2002; a III Parte explora as principais questões políticas e os desafios a nível global e a IV Parte apresenta um plano de ação desenvolvido em redor de objetivos específicos no âmbito do enquadramento dos três pilares de ação ${ }^{4}$ (OIT, Relatório Global 2006, Introdução parágrafos 10,11 e 12, p. 9).

A I Parte do Relatório (parágrafos 106 a 116) além de não analisar nem explicar as causas desse fenômeno, pelo contrário, apresenta algumas argumentações para sua existência, que chegam a ser desconcertantes:, pois,

[...] As crises, sejam elas de origem natural ou humana, são uma característica cada vez mais presente no contexto global em que são feitos esforços de abolição do trabalho infantil.Várias catástrofes naturais afectaram muitos países na região da Ásia e do Pacífico nos últimos anos, a mais dramática das quais terá sido o sismo e subsequente tsunami - o mais mortífero de que há memória - que atingiu a Indonésia, o sul da Tailândia, o Sri Lanka, o sul da Índia, Myanmar e a Malásia, deixando mais de 300.000 pessoas mortas ou desaparecidas. Após o desastre, a vulnerabilidade das crianças aumentou cem vezes. Separados das suas famílias, meninas e meninos ficaram vulneráveis a raptos e em maior risco de serem apanhados nas malhas do trabalho infantil como um dos mecanismos de subsistência adoptados pelas famílias e comunidades sobreviventes. [...]. O trágico tremor de terra que atingiu o Paquistão e outras partes do sul da Ásia a 8 de Outubro de 2005 resultou em mais de 4 milhões de desalojados, para além de ter acabado com mais de 1,1 milhões de empregos e formas de subsistência. (p.40)

Não é de se estranhar o fato de se encontrar, no Relatório, afirmações, como a que segue, mesmo considerando que embora a OIT tenha assistência, nas suas atividades, do projeto UCW (Understanding Children Work) ${ }^{5}$ de cooperação interagências (OIT/ UNICEF e BIRD( Banco Mundial)

As investigações sobre o lado da procura do trabalho infantil são relativamente poucas quando comparadas com as realizadas relativamente à oferta. Se fossem identificadas determinadas actividades profissionais nas quais o trabalho infantil é particularmente rentável, as intervenções no lado da procura 
poderiam ser melhor concebidas e direccionadas. Um estudo efectuado pelo IPEC [...] permitiu obter dados preliminares sobre a relação entre os salários e a produtividade de adultos e crianças. Os resultados do estudo foram ao encontro das expectativas iniciais: pode dizer-se [...] que existem de facto incentivos do lado da procura em determinados mercados de trabalho infantil, e que estudos que permitissem desvendar esses efeitos seriam possíveis e esclarecedores (p.50).

O que deve provocar estranhamento é o fato de não se revelar um segredo escondido a sete chaves: o processo de exploração do trabalho como algo inerente ao capitalismo.

Sem desconsiderar os méritos e intenções de organismos e instituições voltados para eliminação do trabalho infantil, uma primeira leitura que se extrai do relatório é uma propaganda da OIT em benefício próprio, um quadro exibido para impressionar os países que financiam seus programas e, ao mesmo tempo, exploram em outros rincões do mundo o trabalho das crianças, deixando à mostra o desprezo pela vida humana, amenizado por suas milagrosas doações. Segnini (2003, p.40), mencionando artigo intitulado "Enfants exploités", de Ignácio Ramonet (Le Monde Diplomatique, 2002), reitera:

A mundialização liberal não significou mudanças positivas nessa situação; a procura da minimização de custos, entre eles o do trabalho, determinou que mesmo as empresas multinacionais, consideradas modernas, se apropriassem do trabalho infantil, sobretudo exportando a produção para países socialmente precários. Cita o autor, entre outros setores e empresas, o tabaco (Phillip Morris, Altadis), a banana (Chiquita Brands, Del Monte) e o cacau (Cargill). Podemos somar outros exemplos, como a recorrente utilização do trabalho infantil em cadeias produtivas vinculadas a empresas de setores como o automobilístico, calçadista, têxtil (Leite, Márcia, 1996; Lima, 1998). [...] O Brasil tem sido freqüentemente denunciado como um país que explora crianças em processos de produção [...] sobretudo na queima de carvão[...].

Pelo fato do emprego hoje se apresentar como um bem escasso, mesmo na precariedade de condições experimentadas no trabalho, o 
que se vê é o avesso dos direitos. Com a produção e reprodução da vida cada vez mais difícil, a luta travada pelos trabalhadores durante séculos contra o trabalho das crianças se dilui e vê-se uma procura de trabalho radical e dramática para todos os membros da família inclusive pelo trabalho das crianças.

O verdadeiro hieróglifo social, que coloca Marx, não é traduzido, isto é "[...] começa-se depois do fato consumado, quando estão concluídos os resultados do processo de desenvolvimento" [apresentando-se] como "formas naturais da vida social [...]. Refletir sobre as formas da vida humana e analisá-las cientificamente é seguir rota oposta à do seu verdadeiro desenvolvimento histórico" (MARX, 2002, p.97). As iniqüidades das relações sociais responsáveis pelo trabalho infantil são ocultadas. Teatralizase o real, despojando-o de toda história.

Nas palavras de Juan Somavia, diretor geral da OIT, no prefácio do Relatório Global-OIT, 2006, a redução do número de crianças trabalhadoras em todo o mundo, nos últimos quatro anos, é anunciada numa linguagem e estilo quase mágico, principalmente quando se refere ao decréscimo na área dos trabalhos perigosos. "Quanto mais perigoso o trabalho e mais vulneráveis as crianças envolvidas, mais rápida tem sido a quebra". (OIT, Relatório Global, 2006, p. I). Logo a seguir, vem a questão: "Como é que isto aconteceu?" As soluções: educação gratuita, compulsória e de qualidade até a "idade mínima" e "acabar com a pobreza numa geração - nesta geração - é a grande causa global de hoje [...] tal só poderá ser conseguido se o trabalho infantil passar à história”. (OIT, Relatório Global,2006, p. 8).

Todo o relatório está impregnado desse tom profético ou apocalíptico que transporta o leitor o tempo todo do paraíso dos direitos ao inferno do trabalho infantil. O fato é que o capital não pode existir sem explorar a força de trabalho e, no caso do trabalho infantil, a redução do seu custo para o capitalista apresenta-se como um bom prato para essa fome insaciável de trabalho excedente, facilitada pela falta de contratos, pela ausência de remuneração, pela terceirização, pela reedição do trabalho em domicilio e utilização do trabalho doméstico, afinal pela precarização e pelo desmantalamento dos direitos dos trabalhadores.

O que o relatório Global 2006 faz ao apresentar a face caridosa e benevolente do capitalismo com suas políticas públicas e toda sua 
"inclinação" de cuidar bem das crianças é acenar com suas políticas sociais "promessas irrealizáveis, eldorados e paraísos com base no marketing ideológico do para todos" conforme coloca Silva (2003, p.153). E o autor complementa que "[...] quando se trata especificamente de Políticas Sociais aplicadas à infância e adolescência [...] o que está em jogo, o que vigora [...] é justamente a carência de uma política que seja capaz de mudar a vida, de transformar a realidade". ( p. 154).

A leitura do Relatório da OIT vai revelando um verdadeiro encantamento dos criadores frente à criatura. $\mathrm{O}$ seu tom encarrega-se do envolvimento mágico do leitor com a luta contra o trabalho infantil. Tudo se passa como se o trabalho infantil estivesse se instalado magicamente nos diversos quadrantes do mapa sem que se perceba todo o processo de inversão da realidade.

\section{$O$ avesso dos direitos: na defesa do trabalho infantil}

Se no paraíso dos direitos ao não-trabalho há uma representação da criança relacionada à sua falta de "maturidade" tanto social quanto biológica, agora na defesa do direito ao trabalho ela é colocada como protagonista, numa situação diferenciada da anterior.

Através de publicações do IFEJANT1, foi possível mapear alguns autores que propõem a criação de normas legais que protejam o trabalho das crianças da mesma maneira que é regulamentado o direito dos trabalhadores adultos. Esse instituto mantém a publicação semestral da Revista NATs (Niños e Adolescentes Trabajadores) e conta com a colaboração de diversas organizações voltadas para a questão da infância e preocupadas em socializar as experiências realizadas com as crianças trabalhadoras ${ }^{7}$.

A defesa do direito ao trabalho infantil e a recusa às políticas abolicionistas da OIT, embasam boa parte dos artigos da Revista NATs e os argumentos são buscados na Convenção dos Direitos das Crianças (CDC, 1998), especialmente nos Artigos 12 e 13 que defendem o direito das crianças a darem sua opinião em relação às questões que lhes dizem respeito, direito a liberdade de associação e de celebrarem reuniões pacíficas, o direito de serem escutados, de receberem informação e, assim, também coloca em pauta a discussão sobre o protagonismo infantil . 
Entre os autores que defendem a aceitação do trabalho infantil e o protagonismo infantil, destacam-se, entre outros, Manfred Liebel ${ }^{8}$ e Alejandro Cussianóvich'.

Liebel $^{10}$ (2006) não poupa suas críticas referentes ao Relatório Global da OIT - 2006 por anunciar que a redução do trabalho infantil não é um objetivo possível de ser alcançado. Afirma, ainda, que a OIT alardeia dados para

[...] sugerir a la opinión pública (y, al parecer, también a los Gobiernos, a los organismos patronales y a los sindicatos - que constituyen los tres "pilares" de la OIT) la imagen de un trabajo incansable y cada vez más exitoso y, por otro, en todo caso, no alejarse demasiado de la realidad. Al final, ambas cosas no son creibles. (LIEBEL, 2006, p.174).

É também irônico ao se referir às estatísticas, principalmente nas referências da OIT apontando a redução em 11\% de meninos e meninas trabalhadores e $26 \%$ no número daqueles que realizam trabalhos perigosos. O questionamento não se refere apenas às cifras apresentadas em relação às piores formas de trabalho infantil deixando de fixar prazos de erradicação para as demais formas, mas também se refere às categorias e fontes usadas, considerando que elas são

[...] cuestionables e fontes y métodos de medición insuficientes. La definición más amplia de la OIT se refiere a la así llamada "actividad económica" de los/las niños/as. Se excluye de manera explícita las tareas que los niños/as realicen en su propio hogar y el "trabajo escolar". Si bien esta definición de actividad económica incluye también las actividades cuyo resultado no está destinado directamente al mercado, quedan excluidas todas aquellas actividades cuyo fin no es la "generación de plusvalía económica", independientemente de si son o no vitales (p.e. trabajo en el hogar de la propia familia o la producción para el propio sustento de la persona). [...] La OIT sólo habla de "trabajo infantil" que requiere de medidas políticas en relación a aquellas actividades que están prohibidas según las Convenciones de la OIT no. 138 y no. 182. De acuerdo a eso, lo que realizan los/las niños/as mayores de 12 
años que trabajan algunas horas por semana en una actividad permitida y también la actividad laboral de niños/as mayores de 15 años cuyo trabajo es considerado "no peligroso", no es "trabajo infantil". Desde la perspectiva de la OIT, el trabajo infantil sólo es una categoría jurídica y, por lo tanto, es definido por conceptos jurídicos, de los que tácitamente se presume que son "adecuados" y "en el interés" de los/las niños/as. Eso vale también para los/las niños/as que realizan trabajos llamados peligrosos. También esta categoría nace de las pautas jurídicas de las Convenciones de la OIT, especialmente de la no. 182. (LIEBEL, 2006, p. 174)

Além de denominar a avaliação da OIT como uma auto-avaliação, por ser feita pelas suas próprias entidades e não dar a impressão de uma avaliação externa e imparcial, Liebel (2000, p.90) insiste nas suas críticas afirmando que a OIT pouco demonstra saber sobre a magnitude, natureza e efeitos do trabalho infantil, "[...] faltan datos mas fundamentalmente sobre el número de niños que trabajam, lo quehacen, durante cuanto tiempo, qué tareas realizan, se trabajam em condiciones peligrosas o no etc. Esta falta de informaciones detalladas y fidedignas ${ }^{11}$ constituye un obstáculo importante para fijar unos objetivos realistas y concebir actividades eficaces de lucha contra el trabajo infantil [...]". Apesar de reconhecer que vários projetos do IPEC implementados em cooperação com ONGs consideram as condições locais em que se dá o trabalho infantil e inclusive aceitam propostas que venham de outras partes interessadas, critica aquilo que a OIT denomina de "globalização justa".

Na defesa do protagonismo infantil, Liebel (2001) estende suas críticas à pesquisa de Gustavo Pineda e Berta Rosa Guerra (psicólogos) por concluírem que a atitude positiva dos meninos trabalhadores frente ao trabalho deve-se a uma deficiência no patrimônio crítico, a uma dupla alienação pelo fato de, além de considerar o trabalho como um elemento chave de sua identidade, o consideram ainda, como algo extraordinariamente atrativo. (LIEBEL, 2001, p.36). Para Liebel, a pesquisa citada tem como única finalidade desenvolver estratégias para reduzir o trabalho dos meninos e essa é uma posição totalmente contrária à sua.

Argumenta que pelo fato de as investigações serem financiadas por certas organizações que perseguem interesses específicos, inclusive a própria OIT, ficam expostas a interesses políticos, ideológicos e culturais 
dessas organizações que não têm um consenso sobre o que é trabalho e se limitam àquelas atividades e formas de atividades que são "consideradas "negativas", "daninhas", más etc.

Liebel, para tanto, traz a diferença entre labor e work, estabelecida pela OIT em 1990. Sendo o primeiro termo referente a formas daninhas de trabalho infantil (perigosa para a saúde e segurança, limitadora do tempo livre, prejuízo para a educação, orientações instrumentalistas, limitam o contato com os pais ou crianças da mesma idade, enfim trabalho explorado) e a segunda relaciona-se a formas de trabalhos toleráveis (propicia autonomia, confiança na própria força, aquisição de conhecimentos econômicos, experiência de trabalho). Nessa perspectiva, vê o trabalho infantil fortemente influenciado pelo sistema cultural. $O$ autor vai trabalhar com vários exemplos de pesquisas etnológicas e antropológicas nas culturas não-ocidentais para mostrar como a concepção de infância e trabalho se afasta do padrão ocidental. Nas sociedades não-ocidentais, são comuns as formas de "aprender trabalhando" ou de "aprender na vida cotidiana".

Harrán (2001, p.72) é outro autor que defende o trabalho infantil, afirmando que a corrente abolicionista

[...] se fundamenta en una visión moralista y focalista de lo que se considera como una anomalía en la organización social", enquanto a perspectiva defendida por ele "[...] devela la realidad y denuncia una organización social y económica injusta y generadora de pobreza, que presiona sobre la colectividad obligando a utilizar todos los mecanismos posibles de sobre vivencia, y entre ellos el trabajo infantil.

Embora não desconheça as raízes do trabalho infantil ancoradas no sistema sócio-econômico, defende mesmo assim o protagonismo argumentando o seguinte:

Afirmar el derecho al trabajo de niños y niñas no es afirmar la obligación de que trabajen, ni es avalar las condiciones en que actualmente realizan el trabajo. Impulsar el protagonismo social de niñ@s trabajador@s no es justificar el sistema socio económico que presiona por menores costos sociales y mayor rentabilidad, con la consiguiente concentración del capital y del poder; impulsar 
el protagonismo social de niñ@s trabajador@s es denunciar al sistema y unir fuerzas sociales para frenar la ambición neoliberal. Promocionar el derecho al trabajo de niños y niñas no es negar los derechos de la infancia a ser protegida, por el contrario es reconocer al niño/ a como persona protagonista de su propio destino. (HARRAN, 2001,p.173)

Ao defender esse protagonismo, apesar das boas intenções, corre-se o risco de defender uma proposta reformista, considerando ser possível no capitalismo, o trabalho apenas na dimensão de criador da vida humana, de valores de uso, conforme trecho a seguir:

Defender el derecho de niños y niñas al trabajo, es defender el derecho a la dignidad y no marginalidad ni discriminación del niño por el hecho de ser niño o niña que trabaja. Defender el derecho de estos niñ@s, es también asegurar el derecho de estar protegido contra la explotación. Reconocer a los niñ@ @ trabajador@s como sujetos sociales de derechos, es valorar su actividad laboral y por lo tanto dignificar a quienes la realizan; este reconocimiento social favorece el control y protección de losniñ@s trabajador@s contra la explotación laboral. Aceptamos que el trabajo es un valor. Si es un valor humano, es también un derecho humano, independientemente de la edad. Y si es un derecho humano, no se le puede abolir ni prohibir, aunque sí legislar para protegerlo de los abusos que puedan darse. (HARRÁN, 2001, p.174).

Embora alguns argumentos em relação à proibição do trabalho infantil sejam pertinentes na direção de perceber que ela pode culminar em "[...] marginar a aquellos que se pretende proteger, en efecto, al niñ@ además de ser pobre y tener que trabajar, será un marginado condenado a tener que trabajar en la clandestinidad y al filo de la ley”.(p.175), não se justifica, a partir desse fato resvalar para a defesa do trabalho infantil, pois o conteúdo de fundo oculto por trás dessa defesa do direito das crianças ao trabalho, acaba legitimando a exploração do trabalho de crianças diluindo outros direitos como a educação, o lazer, a saúde. 


\section{Protagonismo infantil: afirmação das diferenças etárias ou negação das desigualdades reais ${ }^{12}$}

Vários autores, como Liebel (2001), Figueroa e Cussiánovich (2001) e outros têm o protagonismo infantil como objeto teórico, entretanto Cussiánovich pode ser considerado um dos principais divulgadores desse enfoque naAmérica Latina, considerando suas inúmeras publicações sobre o tema. Ensayos sobre infância (2006), extensa obra sua, gira em torno do protagonismo infantil e logo na introdução, ao mesmo tempo em que indaga sobre a dificuldade que se tem de reconhecer as crianças como atores, sujeitos sociais, culturais, políticos e econômicos, coloca a necessidade de conhecer como tem sido gestada no tempo a idéia de infância. O caminho que o autor se propõe a percorrer passa pela construção, desconstrução das imagens, idéias e representações sociais sobre a infância. A essas idéias o autor acrescenta a "Pedagogia da ternura" como um componente fundamental da promoção do protagonismo.

O protagonismo aparece como elemento central da experiência de construção e organização dos movimentos sociais de meninos trabalhadores. A palavra protagonismo, segundo Sempértegui (1997) é "uno dos pilares conceptuales y practicos que sostienem laintencionalidad política, social, cultural e essencialmente ética de los Movimientos de Jants en nuestra region". (SEMPÉRTEGUI, 1997, [s/p]). É usada no sentido de ator principal, personagem central, mas sempre acompanhada de um adjetivo: protagonismo integral/participação protagônica. Consideram o protagonismo como característica do ser humano e, em todas as publicações, vê-se uma preocupação de explorar a densidade da categoria, muitas vezes portadora de uma carga religiosa. Assim, coloca Cussiánovich (1997,[s/p] $)^{13}$ :

Protagonismo como lugar de encuentro (arjeion), como punto de unión (arjeuo): No hay protagonismo cuando se separa, cuando se crea o mantiene el desencuentro, cuando se provoca división, confusión, cuando se pretende transformar un lugar para encontrarse con los demás en un lugar en que los demás me pueden encuentrar.

Considerando a atuação do IFEJANTs nos movimentos sociais, especialmente no Movimento de Meninos, Meninas e Adolescentes Trabalhadores (MNNATs), percebe-se a insistência em colocar que o 
protagonismo da criança não é minimizado pelo do adulto, inclusive defendese que "[...] um buen critério de discernimiento em torno al próprio ejercicio del protagonismo consiste em verificar cuanto hemos sido capaces de contribuir al protagonismo de los demás" (SEMPÉRTEGUI,1997,[s/p]).

O exercício do protagonismo infantil implica uma redefinição do poder na sociedade, um frontal questionamento do poder adulto, e em decorrência disso, caminham rumo à defesa de uma nova cultura da infância, recorrendo a autores como Allison James e Alan Prout, destacam deles seis pontos que caracterizam um novo paradigma da infância

1- La infancia como una construcción social;

2 - La infancia como una variável de análisis social. No puede ser interamnete separada de otras variáveis como clase, género e etnicidad;

3 - Las relacioness sociales de los niños y sus culturas merecen ser estudiadas por si mismas;

4 - Los niños deben ser vistos como activos na construcción e determinación de sus própias vidas;

5 - La etnografia es una metodologia particularmente útil para lo estudo de la infancia;

6 - La infancia es un fenómeno en relación ao cual la doble hermenêutica de las ciencias sociales está incisivamente presente. (JAMES y PROUT apud CUSSIÁNOVICH, 1997, [s/p])

Éo discurso do protagonismoinfantil que insiste na necessidade de repensar a criança não só como beneficiária de direitos, mas como sujeito social de direitos que não quer ser cidadã do futuro e sim do presente. Os autores vão argumentando que, ao encarar essas dimensões, não há nelas uma idealização nem mitificação do trabalho infantil, porque essas crianças, por terem começado a trabalhar cedo em condições de deterioração crescente, têm uma visão da experiência de trabalhador que levanta sua dignidade, auto-estima e o direito de trabalhar. Insistem na necessidade de uma representação conceitual e afetivo-sentimental positiva que não negue o que as crianças trabalhadoras percebem de outra forma, mas que também não seja ingênua, idealizada, mas representações [...] que dan cuenta de dimensiones y de diferencias personales y culturales que normalmente no se asumem en las representaciones dominantes de infancia " (FIGUEROA; CUSSIÁNOVICH, 2001, p.15). 
Liebel (2001, p.33) também vai na direção da defesa do protagonismo discutindo a investigação participativa com a infância, chamando a atenção para a necessidade de dar voz aos meninos, pois durante muitos anos criticou-se as "investigações da infância sem meninos". Em relação a propostas de investigar o pensamento dos meninos trabalhadores sobre vários aspectos do seu cotidiano, o autor defende que a inserção de crianças na investigação seja de fato uma arma para que as perspectivas das crianças tenham importância e possam ser consideradas na prática pelas organizações de ajuda. Coloca, entretanto, algumas dúvidas em relação a esse aspecto, principalmente pelo fato de as investigações sobre trabalho infantil moverem-se em alta temperatura política.

Ochoa (2003), ao avaliar a perspectiva do protagonismo infantil, o faz com muita cautela, ponderando que o enfoque se encontra "fazendo-se", mas situa a perspectiva de Cussiánovich, um dos seus principais representantes, no contexto da hermenêutica construcionista. Afirma que essa corrente tem adquirido, nos últimos vinte anos, relativa hegemonia nas ciências sociais e assim posiciona-se em relação às principais idéias que têm alicerçado esse discurso da construção social hermenêutica:

En base a varias correntes europeas como son la revalorización de la acción social intersubjetiva sobre las estructuras, el discursivismo, el textualismo, la presença de autores como Foucault, la racionalidade comunicativa, la sociologia interaccionista norteamericana e anglo sajona etc., se señalam que lo social es propriamente una construcción y que las classificaciones sociales con las cuales actuamos en la sociedad, compartimos lazos sociales e asumimos codigos colectivos, son creaciones humanas que funcionam como discursos con los cuales clasificamos e ordenamos la realidad.. La presencia de Foucault es relevante en esta perspectiva. (OCHOA, 2003, p.59).

E o autor ainda completa chamando a atenção para a forma como essa perspectiva hermenêutica tem embasado os movimentos sociais neste século que se inicia. Evita revelar claramente sua posição em relação a tal perspectiva e termina o texto com esta questão: "Limites do construcionismo e do protagonismo?" completada por outras propondo que as respostas sejam buscadas coletivamente, mas chama a atenção para dois aspectos da discussão: 
Por un lado, se necesitamos configurar una sociologia de la infância e por su vez ter discurso de impacto e novedad, a oportunidade que nos brinda lo "enfoque del protagonismo" es excepcional [...]. Pero, por otro lado, no será que também tiene "limites de fuerza" que la obrigan a repensar limando sus excessos e incluso como muestran los enfoques de la psicologia del aprendizaje e sicoanálise del nino a descartala por apresurada e inverosímil.(OCHOA, 2003, p.64)

As perspectivas sobre as quais o trabalho infantil tem sido tratado apontam-no como um mal que deve ser eliminado ou como parte da socialização das crianças, independente de seus efeitos. Aparece nas pesquisas como fonte de orgulho, status e mesmo independência para as próprias crianças, suplementação da renda familiar, atividade essencial para as famílias pobres; o trabalho infantil esconde seus mistérios. Algumas vezes são enaltecidos os seus efeitos benéficos e terapêuticos, sua função dignificadora, antídoto às más companhias, às drogas e aos riscos da rua, à marginalização e à ociosidade. Outros tantos aspectos positivos do trabalho realçam a sua capacidade de propiciar responsabilidade a quem o exerce, criar base de solidariedade, possibilitar aprender ofícios e habilidades etc. Como se não bastasse tais apelos a uma vida de trabalho total, ele se apresenta relacionado a uma dimensão de prazer, sedução, fonte de felicidade, ajuda. Em meio a tudo isso aparece também relacionado à infelicidade e desprazer. Afinal, como coloca Gouveia (1983, p.55) “ [...] decorrente desse modo do menor encarar o trabalho, esse aparece como uma "necessidade transfigurada em virtude".

Muitas perguntas ainda demandam respostas. Qualquer que seja a perspectiva adotada sobre o trabalho infantil, sua compreensão envolve a sua caracterização e da realidade na qual ele se realiza e não é demais repetir que os valores e aspectos culturais que dão sabor ao gosto pelo trabalho têm bases materiais e que, portanto, essa é mais uma forma contemporânea do fetiche edulcorada com a perspectiva culturalista. Por mais que ela seja importante ao realçar o peso do simbólico nas trocas humanas, também traz seus perigos, necessitando perguntar com Chauí (2000, p.12) "quando e por que se passou ao elogio do trabalho como virtude e se viu no elogio do ócio o convite ao vício, impondo-se negá-lo pelo neg-ócio?". 
O problema do trabalho infantil é complexo. Pensar na sua abolição numa sociedade onde reina a mercadoria, é uma fábula e defendê-lo em nome do protagonismo infantil pode ser um impeditivo para que se fortaleçam as discussões referentes a alternativas concretas para as crianças deixar o trabalho.Estas alternativas passam por uma justa distribuição de renda, acesso a uma boa educação, escola adequada.

É preciso cuidado para que o investimento acalorado no protagonismo infantil não anule o protagonismo adulto, e em nome da defesa dos direitos da criança resvale-se para a defesa do trabalho infantil e, mais que isso, ignore-se que no mundo onde impera as mercadorias todo cuidado é pouco para evitar o fascínio fetichista do conteúdo que se esconde por trás das formas.

Num momento em que a precarização do trabalho é uma constante, a destrutividade do ser humano pouco importa ao capital e onde se percebe toda uma mobilização do setor empresarial e autoridades municipais empenhando-se em programas da "Empresa Amiga da Criança" ou "Prefeito Amigo da Criança", soa eloqüente a luta pela proibição do trabalho infantil. Amobilização dos profissionais, instituições, meios de comunicação, sindicatos, entre outros, mostra o tamanho interesse pela causa da criança e do trabalho.

Segundo Delgado (2004, p.74)

La presencia de las transnacionales de la caridad (ONGs) y las declaraciones e intervenciones "humanitarias" de los organismos internacionales (UNICEF, OIT) coinciden [...] con la retirada del Estado y con los efectos producidos por el ajuste. Las ONGs, funcionales ao modelo neoliberal, pretenden aliviar los desastres sociales del enriquecimiento desenfrenado de unos pocos: "aliviar la pobreza" para hacerla más suportable, pero a cambio de que los empobrecidos no cuestionen el modelo que los empobrece, al contrario, terminen aplaudiendo a sus verdugos. En efecto, en la misma medida que se establecen programas para aliviar la pobreza, crece la concentración de la riqueza.

\section{Todo esse movimento leva a}

afirmar sem medo de errar que Marx desmistificou as relações capitalistas e sinalizou que a pobreza por elas criadas acabou sendo ignorada pelo próprio capitalismo ou dada para as entidades 
sociais para desenvolverem a caridade. Neste sentido, Marx demonstrou que a miséria e a pobreza só teriam soluções fora do sistema capitalista (SANTOS FILHO, 2007[s/p]).

As centenas de páginas constantes dos documentos oficiais de organismos nacionais e internacionais sobre o trabalho infantil, juntamente com a luta para sua erradicação, deixam evidentes os limites das propostas de sua abolição assim como expõe a face oculta do capitalismo que gera a pobreza e a inserção precoce das crianças no trabalho produtivo. Deixa aberta a ferida da essencialidade do fenômeno trabalho infantil para o metabolismo do capital. A defesa inconteste do protagonismo infantil pelo direito ao trabalho acaba também por defender a idéia de que haja possibilidade de um capitalismo humanizado, pois como coloca Marx (2002, p.272) "quando se trata de dinheiro, não há lugar para a bondade".

\section{Notas}

${ }^{1}$ Doutora em Educação na Universidade Federal de Santa Catarina e Professora da Universidade Comunitária da Região de Chapecó (Unochapecó-Chapecó-SC).

${ }^{2}$ Pós-Doutora em Educação. Professora da Universidade Federal de Santa CatarinaForianópolis-SC.

${ }^{3}$ Oliveira (1994, p.43) apresenta uma lista com outras convenções e recomendações sobre a idade mínima, emitidas de 1919 a 1973.

${ }^{4}$ Esses pilares referem-se àqueles do plano de ação de 2002: "reforçar o trabalho do IPEC; mainstreaming do trabalho infantil em toda a Agenda para o Trabalho Digno da OIT; e reforçar a acção mundial conjunta". (Ver OIT: Um futuro sem trabalho infantil, Relatório Global no quadro do Seguimento da Declaração da OIT sobre os Princípios e Direitos Fundamentais no Trabalho, Relatório I (B), Conferência Internacional do Trabalho, 95 ${ }^{a}$ Sessão, Genebra, 2006, p.8). A expressão "mainstreaming" diz respeito aos esforços concertados tendo em vista influenciar processos, políticas e programas que têm um impacto significativo na eliminação do trabalho infantil ( p.82).

${ }^{5}$ Lançado em 2000 como resposta a um dos temas principais (cooperação inter-agências) da conferência de Oslo, o projecto UCW foi desencadeado pela OIT, o Fundo das Nações Unidas para as Crianças (UNICEF) e o Banco Mundial. O UCW está actualmente sediado no Centro de Estudos Internacionais sobre Crescimento Económico (CEIS) na Universidade de Roma "Tor Vergata" (OIT, Relatório Global 2006, p.50).

${ }^{6}$ El IFEJANT "Mons. German Schmitz", es producto de una vasta experiencia de cinco organizaciones que conforman desde 1989 la Coordinadora Nacional de Movimientos Hermanos (C.N.M.H): la Juventud Obrera Cristiana - JOC (1935), el Movimiento de Adolescentes, Niñas y Niños Trabajadores Hijos de Obreros Cristianos - MANTHOC (1976), el Instituto de Promoción y Formación de Trabajadoras del Hogar - IPROFOTH (1962), el Servicio de Educación Popular - SEP (1972) y el Instituto José Cardijn IPEC (1984). Nace así, por mandato recogido del III Encuentro de Niños y Adolescentes Trabajadores (NATs) de America Latina y el Caribe (Guatemala, 1992), una institución 
en respuesta a la necesidad de asegurar que los Educadores/Colaboradores de jóvenes, adolescentes y niños trabajadores (JANTs) reciban una formación integral y sistemática. Posteriormente, se ha acogido la invitación del Movimiento Nacional de Niños y Adolescentes Organizados del Perú - MNNATSOP (1996) para dar formación a sus educadores/colaboradores. El instituto lleva como nombre "German Schmitz" (19261990), en homenaje y gratitud a este obispo peruano, infatigable animador de comunidades cristianas, amigo y colaborador de la JOC, quien alentó la creación del MANTHOC, del IPEC y de programas de Formación. Pastor docto, servidor de los pobres, iniciador de multiples experiencias de actores protagónicos: hombre de Dios. (Disponível em <www. Ifejants.org>). Acesso em ago. 2005.

${ }^{7}$ Entre essas organizações, tem-se o MNNATSOP (Movimiento Nacional de NATs Organizados del Peru), MANTHOC (Movimiento de Adolescentes e Niños Trabajadores Hijos de Obreros Cristianos- Peru), Terre des Hommes Bundesrepublik (Alemanha), Acción por los niños, Bice (Poder Crecer), BUTTERFLIES o BHIMA SANGHA (Índia, Nepal, Tailândia), CRECEFOR (Colectivo Regional de Centros de Formación), BROEDERLIJK DELEN (Bélgica), GENERACIÓN (Em defensa de los derechos de las niñas que viven em la calle), SAVE THE CHILDREN (Suécia), VEREIN NATs (Alemanha) Asociazone NATs (Itália), MLAL (Movimiento Laici América LatinaItália) ITALIA NATs.

${ }^{8}$ Manfred Liebel é sociólogo alemão, membro do IFEJANTs, professor da Universidade Tecnológica de Berlim, estudioso das organizações de meninas e meninos trabalhadores, estudando especialmente in loco, na Nicarágua, estes movimentos e em outros países da América Latina, Ásia, África e também na Europa.

${ }^{9}$ Alejandro Cussianovich, cofundador da Revista NATs é docente no Mestrado de Políticas Sociais e promoção da Infância na Universidad Nacional Mayor de San Marcos (UNMSM-Lima-Peru), membro do IFEJANTs e da Rede de Universidades LatinoAmericanas para a Infância.

${ }^{10}$ Uma versão um pouco diferenciada desse texto, também se encontra na mesma obra referenciada, página 169-172, disponível nas referências e pode ser encontrada ainda em www.pronats.de/fileadmin/pronats /documents com o título El nuevo Informe de la OIT sobre el trabajo infantil- um documento presuntoso. Berlim, maio/2006.

${ }^{11}$ Grifos do autor.

${ }^{12}$ Idéia emprestada de Brayner (2001).

${ }^{13}$ Ver texto de Cussiánovich " Los niños del mundo: un reto a la esperanza ya la voluntad política de todos los hombres y mujeres de buena voluntad”. In: Jóvenes y niños trabajadores: sujetos sociales, ser protagonistas. 1997. Disponivel em www. ifejants. org.

\section{Referências}

CHAUÍ, Marilena. Introdução. In: LAFARGUE, Paul. O direito à preguiça. São Paulo: Hucitec/Editora da UNESP, 2000.

CMT (Confederación Mundial del Trabajo). Trabajo Infantil: Campaña internacional por la ratificación y aplicación del convenio 182 de la OIT, 1999. Disponible en <htpp://www.cmt-wcl.org >. Acesso em jun. 2006. 
COSTA, Antonio Carlos Gomes da. A Convenção Internacional dos Direitos da Criança. In; SIMONETTI, Cecília; BLECHER, Margaret;s MENDEZ, Emílio Garcia (Comp.) Do avesso ao direito: da situação irregular à proteção integral da infância e da adolescência na América Latina. III Seminário Latino Americano. São Paulo: Governo do Estado de São Paulo/UNICEF/Brasil: Malheiros, 1992.

CUSSIANOVICH, Alejandro V. Aprender la condición humana: ensaio sobre pedagogia de la ternura. IFEJANTs, 2006.

. Ensayos sobre infância: sujeto de derechos y protagonista. IFEJANTs, 2006.

. "Los niños del mundo: un reto a la esperanza ya la voluntad política de todos los hombres y mujeres de buena voluntad”. In: Jóvenes y niños trabajadores: sujetos sociales, ser protagonistas. 1997. Disponível em: http:/ /www.ifejants.org. Acesso em: ago. 2007.

FIGUEROA, Elvira e CUSSIANOVICH, Alejandro. La organización: espacio de resiliencia y herramienta para el protagonismo de los NATs. In: NATs (Revista Internacional desde los Niños y Adolescentes Trabajadores). n. 7-8, p.11-32, Jun/2001.

GOUVEIA, Aparecida J. O trabalho do menor: necessidade transfigurada em virtude. In: Cadernos de Pesquisa, nº 44, p.55-62, fev/1983.

HARRÁN, Javier. Reflexiones sobre el derecho de los niños trabajar. In: NATs (Revista Internacional desde los Niños y Adolescentes Trabajadores). n. 78, p.167-177, Jul/2001.

LIEBEL, Manfred. Investigación participativa sobre la infância, entre acaparamiento y solidaridad: dos estúdios com ninños trabajadores in Centroamérica. In: NATs (Revista Internacional desde los Niños y Adolescentes Trabajadores) . Año V, n. 7-8, p.33-46, jul./2001.

.Repensar la mirada adulta. Pobreza infantil, trabajo infantil y la nueva subjetividad de la infância. In: NATs (Revista Internacional desde los Niños y Adolescentes Trabajadores). .Año VI, n. 10, p.29-43, Mayo/2003. 
. Historia de éxito o desorientación?El nuevo informe de la OIT sobre

el trabajo infantil. In: NATs (Revista Internacional desde los Niños y Adolescentes Trabajadores), Año VII, n. 15, p.174-179, set/2006.

.Entre prohibición y elogio. Aspectos ocultos del trabajo de niños em sociedades post-industriales. In: LIEBEL, Manfred. Malabaristas del siglo XXI: los niños y ninas trabajadores frente la globalización. IFEJANTs, 2006, p.157-188.

. La outra infância: niñez trabajadora y acción social. IFEJANTS, 2000.

MARX, Karl . O capital: crítica da economia política: livro I, $20^{\mathrm{a}}$ ed. Rio de Janeiro: Civilização Brasileira, 2002.

MDS (Ministério do Desenvolvimento Social e Combate à Fome)/ SAGI (Secretaria de Avaliação e Gestão da Informação). Nota Técnica 2006 - SAGI/ MDS. Análise dos dados sobre Trabalho Infantil na PNAD. Brasília, 2006.

MESZÁROS, Istvan. Para além do capital. São Paulo: Boitempo, 2002.

OCHOA, Manuel Castillo. El protagonismo infantil o las possibilidades e limites del construcionismo. In: UNDA, René et al. Infância y adolescência em América Latina: aportes de la Sociologia. IFEJANTs, Peru [s/d] .XXIV Congresso ALAS 2003. Tomo I.

OIT (Organização Internacional do Trabalho). O fim do trabalho infantil: um objetivo ao nosso alcance. Relatório Global no quadro do Seguimento da Declaração da OIT sobre os Princípios e Direitos Fundamentais no Trabalho, Relatório I(B), Conferência Internacional do Trabalho, 90ª Sessão, Genebra, 2006.

OIT/2002.

Um futuro sem trabalho infantil . Suplemento do Relatório Global.

.Guia sobre las normas internacionales del trabajo. $<$ Disponivel em: htpp//www.ilo.org. Acesso em set./2006

OLIVEIRA, Oris de; PIRES, Júlio Manuel. O trabalho da criança e do adolescente. In: FERNANDES, Reynaldo (Org.). O trabalho no Brasil no limiar do século XXI. São Paulo: LTr, 1995. 
OLIVEIRA, Oris de. O trabalho da criança e do adolescente. São Paulo: LTr, Brasília: DF:OIT, 1994.

SANTOS FILHO, João dos. A situação das crianças retratadas nas obras do mouro- O Capital (III). In: Revista EspaçoAcadêmico, n.79. Dez./2007.

SEGNINI, Liliana R. P. Mulheres, mães, desempregadas: contradições de uma condição social. In: SÃO PAULO. Prefeitura Municipal Coordenadoria Especial da Mulher Trabalho e cidadania ativa para as mulheres: desafios para as Políticas Públicas / Emílio, Marli et al. (Orgs.). São Paulo: Coordenadoria Especial da Mulher, 2003.

SEMPÉRTEGUI, Elvira Figueroa. Jóvenes y niños trabajadores: sujetos sociales, ser protagonistas. IFEJANTs, 1997.

SILVA, Maurício Roberto da.Trama doce-amarga: (exploração do) trabalho infantil e cultura lúdica. Ijuí: Unijuí; São Paulo: Hucitec, 2003.

.Recortando e colando as imagens da vida cotidiana do trabalho e da cultura lúdica das meninas-mulheres e das mulheres-meninas da zona da mata canavieira pernambucana. In: Cadernos Cedes, ano XXII, n. 56, p.23-52, abr.2002.

\section{Abstract:}

\section{The opposite of children's right: eradication of childhood labor on debate}

This text places two contradictory perspectives related to the end of childhood labor: the perspective of OIT (International Work Organization), in defense of its ending, and other opposite to it, in defense of the critical value of the work developed by children, perspective that insists on the child protagonism, that is, the need to give voice to children in dimension of what they have to say about work.

Keywords: Childhood labor. Childhood protagonism. Eradication of childhood labor. Children's rights.

Recebido em dezembro de 2009.

Aceito em maio de 2010. 